\title{
The Grimace of Ambiguity: Unambiguity and the Critics
}

\author{
Richard Chamberlain
}

\author{
University of Northampton, St George's Avenue, Northampton ,NN2 6JD,UK \\ *Corresponding Author: Richard.Chamberlain@northampton.ac.uk
}

Copyright (C) 2015 Horizon Research Publishing All rights reserved.

\begin{abstract}
This article considers the notion of ambiguity and its treatment by critics and theorists from a perspective informed by the work of Slavoj Žižek, according to which ambiguity should not be conceived as an exceptional 'grimace' of language's deeper, more genuine 'Unambiguity'; rather, the pervasive fantasy of Unambiguity should be thought of as the grimace of ambiguity - a convenient invention whose function is to mask the Void of a generalised indeterminacy feared by literary critics. It examines not only ambiguity's ideological functions in literature, but ideology's role in the critical conceptualisation of ambiguity. Eleanor Cook's article, 'Ambiguity and the Poets', is taken to exemplify the much-maligned concept's strangely persistent usefulness for an enriched understanding of poetry, but also the contradictoriness of the positions adopted by liberal interpreters. Revisiting poems by Elizabeth Bishop and Wallace Stevens discussed by Cook, and adding a reading of Tess Gallagher's 'Instructions to the Double', the article demonstrates 1) the social character of ambiguity in those texts, and 2) how the moral hesitation about linguistic instability evident in the language of Cook's article - ambiguity's 'mixed reputation' - highlights anxieties around sexual and economic power within critical discourse. Critics' implicit and ever-frustrated desire for 'Unambiguity' (an ideal of stable semantics and a correspondingly well-ordered society) is symptomatic of the contradictions of their historical moment and the bourgeois assumptions of 'traditional' literary criticism. It is therefore proposed, in conclusion, that unblinking attention to the unfinished, ambiguous nature of social and linguistic reality is a more effective path to political change, and indeed to the effective appreciation of poetry, than unspoken appeals to this fantasy of unachievable Unambiguity.
\end{abstract}

Keywords Unambiguity, Poetic Ambiguity, Elizabeth Bishop, Tess Gallagher, Ideology, Indeterminacy, Wallace Stevens, Slavoj Žižek

But one only woke people if one knew what one wanted to say to them. And she wanted to say not one thing, but everything. Little words that broke up the thought and dismembered it said nothing. 'About life, about death; about Mrs Ramsay' - no, she thought, one could say nothing to nobody.

Virginia Woolf, To the Lighthouse
According to Eleanor Cook, in her article 'Ambiguity and the Poets', the term ambiguity is currently out of favour amongst critics and theorists. In part, she argues, this is because its usage at one time became so vague that it had virtually lost all meaning, and partly because it has of late been replaced by talk of a thoroughgoing 'indeterminacy' in the wake of deconstruction's contribution to debates about multiple meaning and the problems of interpretation. She indicates that this is a matter for some disquiet, as the waning of ambiguity seems to imply the end of attention to aesthetic particularity in literary studies. ${ }^{i}$ However, since her article was published (in 2008), interesting discussions have continued to speak of 'ambiguity', suggesting that the term might have unexpected longevity. If ambiguity is indeed refusing to go quietly, it may offer some useful historical perspective on the many recent theorised explorations of plural meaning in literature; I think it is important, however, that we should use and think about the term in ways which keep the important questions open, rather than embracing it in a nostalgic return to an older, more comforting, set of assumptions. Throughout its modern history in the language of criticism, ambiguity has had both an enigmatic and a recalcitrant quality. Empson, who played a large role in propelling it to the forefront of critical discussion in his Seven Types of Ambiguity (1930), recognised its inherent difficulty, and yet (once we are started on the search for it) irresistibility. His book is so important, not just because it is so good at spotting ambiguities, but because it shows how the problem of ambiguity goes to the heart of the critical activity itself, as when he says at the outset that 'Sometimes ... the word may be stretched absurdly far, but it is descriptive because it suggests the analytical mode of approach, and with that I am concerned.' (Empson 1)

Cook's central concern is to demonstrate, through a series of close readings, that (against the recent preference for indeterminacy) the notion of ambiguity still has great efficacy for demonstrating the richness of the 'many-sided' meaning in poetry, and she draws upon earlier theorists such as William Empson, W. K. Wimsatt and Cleanth Brooks, and Winnifred Nowottny, whose thinking preceded the 'deconstructive turn', for the conceptual basis of her approach. By contrast, recent contributions by, for example, Betty Rojtman, Dominique Vaugeois, and David G. Brooks place the topic in a more topical, poststructuralist-tinged 
problematic and raise issues of desire and the relationship between ambiguity and 'reality'. Whether openly or implicitly, these older and newer approaches all suggest that ambiguity reveals more about the position of the critic or theorist than about the literary text, and this is something I shall take as my starting-point here. In contrast to the majority of these discussions, however - which appear to take for granted that the topic of ambiguity is a politically neutral one - I shall attempt to think-through the issue of ambiguity from a materialist perspective, making use of the framework provided by Slavoj Žižek's re-reading of Lacan, in order to explore the ideological dimension of the critics' reflections upon poetic ambiguity. Such an exploration suggests that critics and theorists of ambiguity working within the assumptions of a liberal-capitalistic culture (as to some extent, given the historical moment we inhabit, all those of us in Western intellectual life must) tend to be driven, often unknowingly, by the desire for an ideal Unambiguity, a phantasm which defines the limits of their understanding and their sense of reality.

\section{1. 'Ties' and 'Tears': Art and Ambiguity}

Before passing on to examine 'Unambiguity', it is worthwhile considering the merits of the 'traditional' mode of critical analysis via ambiguity which, I am going to argue, is haunted by that negative spectre. It is important to recognise the power of the concept, and how, even for these earlier interpreters, plural meaning is bound up with the very nature of literary art and the ways in which we try to understand it. Winifred Nowottny, in The Language Poets Use, writes of

a real connection between art and ambiguity, in that the ambiguity inherent in the medium itself serves as a bridgehead between 'things as they are' and the significance that may be imputed to them. The ambiguity of the medium enables the poet to meet that double demand that we make of the language of poetry, that it should deal both with the phenomenal world and with the world of values. (Nowottny 162)

Empson asserts that 'the machinations of ambiguity are among the very roots of poetry' (Empson 3), arguing similarly that the 'many-sidedness' of the artistic medium is what enables it to illuminate the complexity of the world of cultural experiences and values, but more specifically of social values. In the passage just quoted, which concerns Shakespeare's line 'Bare ruined choirs, where late the sweet birds sang' (Sonnet 73), Empson shows that his sense of the richness of association in a poem is deeply connected with its complex rootedness in social life, which ranges all the way from the qualities the poet might have found sexually alluring to the psycho-social impact of the dissolution of the monasteries. The ambiguity of the poetic medium thus makes it possible to grasp the many-sidedness of social value systems and the conflicts within them, out of which the poems have grown and within which they are read.
In 'Ambiguity and the Poets', Cook's reading of Elizabeth Bishop's 'Chemin de Fer' is an effective demonstration of ambiguity in action, but it gives a sense that the poem's ambiguity can be noted, but must be swerved from before its social implications are seen to take on a political character. It begins from a lexical ambiguity which then acts as a thematic key for the whole text: the hesitation over whether the 'ties' in the third line refer to part of the railway track (the sleepers), suggesting the imminent possibility of a crash, or whether the 'ties' are emotional ones, suggesting ambivalence about a relationship possibly both suffocating and distant, with a sense that the speaker is in flight from an unbearable personal situation:

\section{Alone on the railroad track I walked with pounding heart. The ties were too close together or maybe too far apart.}

The text is ambiguous in form and execution (its wording), and this increases the extent to which ambiguity of situation and emotion are themes of the poem. In particular, the reader's feeling of being torn between semantic alternatives reinforces their appreciation of the speaker's traumatised self-division. Further, the ambiguity around 'ties' mingles, or ties, together perceptions of the physical world with the 'values' of emotional experience to create a powerful, yet open-ended artistic representation.

In both the ties and the uncertain echoes, the poem exploits interplay between the physical environment and the reflective mind, accentuating the way poetic form acts as mediator between world and idea, and this artistic mediation through ambiguity also becomes part of the overarching theme of the poem, along with its exploration of a confused or traumatised state, and (to go beyond Cook's reading of it) of alienated social, as well as personal, experience, within which 'ties' of all kinds have stopped making sense. A dynamic modern transport system, the railway, makes the perfect ironic vehicle for a poem dwelling upon stasis or entropy - emotional, intellectual, and, obliquely, historical. This alienated social experience is symbolised in the drear landscape through which the speaker moves:

\footnotetext{
The scenery was impoverished: scrub-pine and oak;

beyond its mingled gray-green foliage I saw the little pond

where the dirty old hermit lives, lie like an old tear

holding onto its injuries lucidly year after year.
}

These stanzas are centred upon a second major ambiguity, that between 'tear' as a rent or injury and the 'tear' one weeps, two different words which, as the poem demonstrates, are intertwined in its portrait of traumatic emotions, but which might also have led to an analysis of the poem's ruminations on a world of relationships alienated by the system of society. As a wound in a surface, the 'tear' remains 
a trauma which cannot be healed; as a droplet of salt water, it remains 'lucidly' clear-sighted and undeceived about what has occasioned it: an image which speaks of the need to face, rather than wink at, 'injuries' or injustice, and also to feel what others feel, because this lucid teardrop is a universal one, distilling tragic historical memory.

\section{Late for Dinner: Ambiguity and Ideology}

Other approaches are less reticent about this collective element to the emotional complexity registered in poetry. That of Dominique Vaugeois contrasts with Cook's in that she emphasises the degree of social power at work in acts of interpretation and the ways we understand the nature of ambiguity. That power, she argues, depends upon the interpreter's own position, the limitation or 'blind spot' (Vaugeois 443) which makes their point of view possible. Such a position is necessarily bound up with various kinds of social power: 'The blindest part of our blind spot is almost certainly our knowledge of our own position while we observe another subject. And of course, this position need not be restricted to spatial and sensorial coordinates, but also social, economic, historical, gender coordinates that we do not ourselves master.' (Vaugeois 443) Her taking into account of the social might usefully illuminate the meditation upon historical trauma via ambiguity in Bishop's poem to a greater extent than is possible through the liberal humanist assumptions about ambiguity and the role of the reader operative in Cook's account.

This element of the local perspective of the critic, positioned within the structures of the social order, becomes apparent in examples from a number of critics and theorists in which a tone of moral condemnation is used in speaking of ambiguity, and even in referring to an author who fails to exclude it appropriately. For example, according to Cook, ambiguity is 'the bane of translators, who must decide whether it is intentional or merely casual, and if casual, whether the author is careless or lazy or ignorant.' (Cook 230). The choice appears to be between crediting the sagacious author with intentional manipulation of ambiguity as a literary device, and charging him or her with morally culpable carelessness, laziness, or plain ignorance - in other words, with a failure to maintain their defences against ambiguity, thought of as the insidious decay that language and the world inevitably bring with them. Thus, occasionally Ambiguity (Cook's sometimes personified representation of her/it sometimes cries out, in vain, for a capital A) can be a 'guest' (Cook 230) who is 'useful and even welcome' (that is, when intended), and decidedly bad news at other times (that is, when she represents a failure of authorial control): 'She [A/ambiguity] is disliked and avoided in some realms' (Cook, 230). In short, there is a drawing of boundaries, a creation of separate 'realms', which the personified Ambiguity is prevented from freely traversing, unless there is some censurable laxity in the police.
There is thus an ideological dimension to the morally-charged language that often colours the depiction of linguistic ambiguity. This feature of natural language is tolerated only selectively by civilisation, an aspect of the wild with which bourgeois citizens must for their own good now and again reconnect (through poetry), but which, if left unchecked, would be harmful to both property and propriety. Cook's implied audience might be imagined as a constituency of respectable burghers, appalled at the prospect of uncontrolled meaning: "We do not want ambiguity in legislation. Nor do we want it in our wills or in our financial affairs.' (Cook 230) These concerns, at once socially exclusive and presented as universal by the plural pronoun, assume that 'we' have 'financial affairs', or much to leave in 'our wills', a state of affairs which continues to elude the majority of people on the planet. Unambiguous legislation, held up as another good reason to shut Ambiguity out in the cold, also serves the cause of property, inheritance, and the orderly transmission of wealth. Even an amusing anecdote about Canadian 'collector lanes' might be read through such a lens. In the story, Cook's Australian visitor inadvertently breaches one polite protocol (punctuality) in an attempt to honour another (financial prudence), when he falls prey to ambiguity: 'He assumed - logically enough - that these were toll highways, collecting money, and so avoided them, overshot the city, and was late for dinner. In fact, collector lanes simply siphon off - that is, collect - traffic that is preparing to exit.' (Cook 230)

Cook points out that $\mathrm{A} /$ ambiguity is 'welcome' to liars, unreliable oracles like the witches in Macbeth, writers of equivocal employment references, and so on, before proceeding to show how ambiguity is so important to poetry. This shows that the 'mixed reputation' of Ambiguity does not arise from different preferences, but rather, that Ambiguity can be a source of hesitation in one and the same mind, and indeed within a key ideological formation structuring the world-view of capitalism. The liberal discourse on ambiguity is irritated by this dilemma: whilst Ambiguity subverts the lucid semantics needed for good business, she is integral to Literature; Literature (or its idea) in turn plays an important role in ideologically legitimising the existing social order by aestheticising it, naturalising it, or by claiming to 'transcend' it, at least when it is taught in certain ways.

This gesture by which Ambiguity is simultaneously ushered into poetry and excluded from 'life', recurs frequently in the critical literature on plurality of meaning. Empson notes, from the outset, that 'An ambiguity, in ordinary speech, means something very pronounced, and as a rule witty or deceitful.' (Empson 1) [my emphasis] Moreover, it is partly because of its pejorative connotations that Winifred Nowottny suggests replacing the term 'ambiguity' with 'extralocution':

In discussing the poet's use of the potential ambiguity of language at large, we need some term likely to act as a corrective of the tendency to associate ambiguity with a censurable ineptitude in the use of words. A term 
suggestive of success rather than failure might help us out of some critical difficulties that follow from the entertaining of unreal notions of the processes by which meaning is established. For however true it may be, in theory, that the Empsonian approach to ambiguity 'permits a fresh and searching examination of literary works', [quoting Dictionary of World Literary Terms, ed. Joseph T. Shipley (London, 1955), p. 15] this or any comparable approach is likely to excite misunderstanding and even irritation if it appears to advocate as a virtue what many of us have been taught to regard as a vice. (Nowottny 155) [my emphasis]

As Geoffrey N. Leech puts it, 'If an ambiguity comes to our attention in some ordinary functional use of language, we generally consider it a distraction from the message and a defect of style. But if it occurs in a literary text, we tend to give the writer the benefit of the doubt, and assume that a peaceful coexistence of alternative meanings is intended.' (Leech 204) [my emphasis]. Literature is thus a space in which we are prepared to see ambiguity as deliberate. Moral condemnation does not apply as long as we can reasonably consider the context to be literary.

Similarly, according to Soon Peng Su,

Positive value is given to ambiguity in literature because the process of producing a literary piece, involving numerous rewritings and revisions, reduces the likelihood of accidental ambiguities. This leads to the assumption on the part of literary critics that ambiguity in literature, and poetry especially, is deliberate and contributes to the larger design of the work. (Su, p. 6)

This suggests that accidental ambiguity is to be considered a fault (one condemned, as Su notes on the same page, by Aristotle), even in Literature, although the nature of Literature supposedly reduces the likelihood that any plural meanings will not fit into the authorial design. Plainly, there is an assumption by these theorists that the deleterious effects of ambiguity in 'ordinary language', whether accidental, deceitful, or the result of simple showing off, can be ameliorated, even fully controlled, by the artistic creator. Literary ambiguity is regulated transgression, a creative walk on the wild side, but not too far on the wild side. It is as if the author's proprietorial control over the literary text creates a privatised space in which they can be as ambiguous as they like behind closed doors without causing offence to the surrounding community.

\section{Cherchez la Femme: Ambiguity and Sexual Politics}

As we have seen, Cook demonstrates, through 'Chemin de Fer', how ambiguity, conceived both as a verbal quibble and as a division in the mind, powerfully underlies literary effects. Furthermore, such a division is also characteristic of her own, and other critics', (re)presentation of ambiguity. Indeed, the imagined world of alienated erotic experience in the poem, with its speaker wandering onto the wrong side of the tracks, to encounter those, like the hermit, who have been wounded by love, echoes the critic's characterisation of Ambiguity. The first two sentences of the article both personify and gender the phenomenon of ambiguity strongly:

A stranger meeting ambiguity for the first time might well be taken aback by her mixed reputation. She is disliked and avoided in some realms, whereas in others she is welcome. A philosopher like J. L. Austin will patrol the streets of language in order to identify ambiguity in his book, How To Do Things With Words. (Cook 230)

This figure, appearing in the opening sentences of Cook's article, excites both attraction and suspicion: Ambiguity (Cook's humorous character sketch cries out for the capital A) is the kind of character who might have escaped from a hardboiled detective novel. Ambiguity has a 'mixed', or ambiguous, reputation. Of course, 'reputation' is itself an ambiguous phenomenon, of dubious origins and value, and prone to manipulation. Cook paints a shadowy world in which a woman of dubious or, at best, 'mixed' reputation encounters strangers in morally ambiguous situations. There seems to be a strong implication that Ambiguity is to be (or often just is) considered morally reprehensible, unreliable and untrustworthy. In this somewhat noir fable, she is false, inauthentic, even meretricious. This offender against conventional morality and property is, however, imagined as under the watchful eye of the conceptual police, led by Austin and the philosophers of language. ${ }^{\text {ii }}$ This colourful representation of linguistic ambiguity which, overtly at least, only lasts for a sentence or so, is an interesting symptom of the tendency for critical discussions of ambiguity to accrue both moral and gendered dimensions. There is felt to be something suspect about ambiguity (or Ambiguity) and on that basis a parallel is implied between proliferation of meanings and the allegation of unreliability in Woman.

Whilst traditionally-minded critics and theorists have tended to linger in this dilemma, finding Ambiguity at once distasteful and irresistible, poetry has explored these questions in much more incisive and unabashed ways. Tess Gallagher's 'Instructions to the Double' wittily explores the politics of the way in which double meaning and sexual duplicity tend to be attached to Woman by members of the patriarchal literary and social 'country club'. The poem plays on the doubling or multiplying of its speaker's identities. The title may mean both 'instructions to the speaker's alter ego' and 'instructions to be carried out at the double, without hesitation or quibbling':

\section{So now it's your turn}

little mother of silences, little father of half-belief. Take up this face, these daily rounds with a cabbage under each arm convincing the multitudes that a well-made-anything 
could save them. Take up

most of all, these hands

trained to an ornate piano

in a house on the other side

of the country.

The 'Double' of Gallagher's poem is of questionable, or plural, gender: it appears to be both 'little mother of silences, little / father of half-belief'. Whilst Cook's critical theory appears to introduce the feminine Ambiguity, only to change her immediately into an 'it', Gallagher's poetic speaker relishes the many-sidedness of her creation. The mother here seems to represent the silencing of women within patriarchy, the father ineffectual courage. This creature of mixed gender is being sent out into the world, having taken up 'this face' and 'these hands', to take its 'turn', the speaker herself having apparently given up the effort of living in such a punishing world.

In the poem's second paragraph, the Double is urged to go into the world precisely as a creature of 'mixed reputation', playing many of the roles one could imagine being adopted by Cook's Ambiguity. For instance, there is the femme fatale, Cook's wayward, enigmatic will-o'-the-wisp, dangerously promiscuous with meaning, truth and identity:

Get into some trouble

I'll have to account for. Walk

into some bars alone with a slit in your skirt. Let the men follow you on the street

with their clumsy propositions, their

loud hatreds of this and that.

The poetic treatment of these problems here indicates the possibility of an approach to ambiguity which eschews the questionable distinction between poetic and other kinds of language, and the reliance upon the author's intentions necessary to maintain this distinction. Moreover, the poem makes a virtue out of the connections between the apparently technical issue of poetic ambiguity and the impact of social power.

Nowottny attempts to get around the moral double standard habitually applied to ambiguous language, but her analysis, in introducing the concept of 'extralocution', although fascinating and ingenious, still clings to the supposed reassurance of intentionalism:

A tolerable term for these cases might be the term 'extraloquial', if one might suppose that it would suggest having extra meaning or leaving extra meaning in... Having more meanings than one is the result of not entering into the full commitment of unequivocal assertion .... Extralocution is a stopping short of complete specification, of the maximal exclusion of alternatives ... to use a word or phrase extraloquially is to refrain from limiting the potential of the context, whilst at the same time drawing attention to the potential. (Nowottny 155-6)

Rather than an excessive invader and multiplier, like the femme fatale Ambiguity, extralocution is marked by restrained self-control. Ingeniously, what is refused is not excess but limitation itself. The poet is free to demur from common sense and thus to stop herself from excluding alternative possibilities. From this point of view, poetic madness becomes a case of self-possession, of having sufficient confidence to let readers make up their own minds. The beauty of this reversal is that it allows the critic to celebrate and explore the artistic resources opened up by the coexistence of so many possibilities, whilst forestalling moralistic accusations of irresponsibility in literary criticism.

It does not, however, get around the central problem: that the theory of ambiguity exhibits such a strong desire - and it is a desire rather than an achievable aim - to corral plurality of meaning within the exceptional zone of the poetic, whilst preserving the integrity of an essential realm of unambiguous 'ordinary language'. Indeed, despite noting, via Charles C. Fries, the falsity of the idea that there is a 'basic' meaning for each word, against which all others are 'figurative' or 'illegitimate' (Nowottny 159), Nowottny's notion of the 'extra', allowed to remain in the 'extraloquial' (as she notes, 'the prefix "extra-" is often outside or apart from' (Nowottny 156) assumes that these ambiguous possibilities are exceptional, and thus poetic, rather than themselves merely ordinary. Ultimately, her version is as much a fantasy of the author's sovereignty over meaning as any other critic's. By contrast, Gallagher's poem celebrates the morally questionable qualities which have been attached to linguistic and artistic ambiguity by critics and theorists, suggesting that the 'mixed' attitude to a feminised ambiguity is in part an expression of patriarchal uneasiness about women's emancipation, internalised by both male and female commentators. The men here are loud, boorish and stupid. The female Double provokes but also eludes their meanings:

Slut, mother,

virgin, whore, daughter, adulteress, lover,

mistress, bitch, wife, cunt, harlot,

betrothed, Jezebel, Messalina, Diana,

Bathsheba, Rebecca, Lucretia, Mary,

Magdelena, Ruth, you - Niobe,

woman of the tombs.

It enjoys the multiple potential, and the unravelling of fixed and naturalised identities, in this 'Double' who might, in double-quick time, transgress the limits of existing social relations.

\section{4. 'The Possible Meaning of Surprise': Unambiguity and the Real}

In trying to understand why the critics are torn between positive and negative reactions to ambiguity in language and art, I want to argue that it is necessary for criticism to recognise the pull of a powerful attraction which has a distorting effect on everything it does. It us useful, here, to think in terms of Žižek's understanding of the relation between 'reality' and 'the Real'. The critics' negative reactions to ambiguity, which even those who (like Nowottny) celebrate its poetic versions seem unable to 
refrain from mentioning, evince a deep need in the culture of letters represented by Gallagher's 'country club' for something as yet un-named, something strictly impossible, which we might call Unambiguity.

The fantasmatic female, Ambiguity, who haunts the critics' reflections upon plural meaning implies another figure, an opposite, who defines her identity even as she defines his. If the ideological framework informing the 'commonsense' or 'ordinary language' approach to ambiguity tends to characterise it as an untrustworthy (yet indispensable) mistress, who twists what is assumed to be the primordially unambiguous nature of language, this opposite, 'Unambiguity' must be imagined as male, reliable, authoritative, rational, honest and honourable. In short, Old Man Unambiguity is logically entailed (although never openly mentioned) within the liberal-patriarchal discourse of bourgeois literary criticism and theory as the defining other of his flighty nemesis, Ambiguity. He personifies the commonsensical assumption of a general correspondence between words and things, and therefore of the transparency of language as a means of representation. He is not named precisely because he is the assumed norm. Nevertheless, Unambiguity is no less phantasmatic for all that: he is the necessary fiction so necessary that his presence is never consciously recognised. To view matters from the celebratory perspective of Gallagher's speaker, Ambiguity does not have a 'mixed reputation', but rather embodies the quality of mixed-ness itself (pied, variegated, motley - plural, dazzling, unsettling, and alive); conversely, Unambiguity is so grey as to be near-invisible: he stands for silence, for sameness, and for death.

Thinking-through these problems in terms of Žižek's philosophical and psychoanalytic interrogation of 'reality', we can see (as a starting point) that although reality is generally assumed to be stable, to be what it claims to be, we are nevertheless often presented with aspects of it which are bizarre, unaccountable, uncanny, or just too overwhelming to contemplate. This everyday or ordinary reality is all too easily infiltrated by a disturbing otherness, a fundamental ambiguity or unknowability. Once we recognise this incomplete or contradictory nature of reality, it is tempting to see it not as a natural fact, but as collective construct created in order to make bearable a life dependent upon the chaos of 'ordinary language'. Thinking of it this way, the troublesome figure of Ambiguity, rather than being a perverter of plain speaking, starts to be identifiable with the inherently troublesome, flawed, unreliable medium of language itself, out of which we struggle with only partial success to fashion a viable life-world.

It is interesting to compare the view of these questions implied in Betty Rojtman's understanding of interpretative traditions around the Book of Esther. According to these, she argues, the divine is revealed by its concealment in apparent 'coincidence'; only at the moment of Revelation does everything become overt and 'chance' disappear.

According to rabbinical logic, God indeed intervenes in history, but in such an indirect way that the event is shrouded in natural causation. The only trace that remains of Providence is precisely the marks of coincidence, the inexplicable happenstances that create a gap in everyday normality, equally capable of "falling under" pure contingency or theological necessity. ... Only under such conditions of silence, of night, and of exile, only in the apparent omnipotence of chance may there be some proof of the possible meaning of surprise, of a meaning born of its own contingency: in other words, of a logic of discordance, of a discordance that finds its ultimate logic without, however, losing its discordant nature. (9)

From the obscured perspective of the material world, we have to rely upon coincidence to break through the shell of habitual reality to reveal 'the meaning of surprise'. By analogy, the everyday 'hiddenness' of meaning in ambiguity seems to critics and theorists to point to an underlying state of revelatory Unambiguity; the richness of literary language in its open-ended plurality ultimately, and paradoxically, signifies the author's self-assured grasp of a univocal truth.

Similarly, Domique Vaugeois's metaphors of the blind spot and the 'horizon' presuppose that the key to correct, univocal or unambiguous interpretation is somehow always present, even though out of sight. Unfortunately, however, the impossibility of such a master-interpretation is constantly reasserted by the symbolic structure of language. The very fact that the absence (but presence elsewhere) of the key to meaning has to be constituted as a metaphor - a carrying-across, a differing and deferring - underlines the impossibility of that kind of transcendent answer. The metaphor (in this case, from optics) performatively negates the idea it is intended to communicate. The imagined Unambiguity just around the corner is a phantasmatic resolution of the problem of irresolvable, endemic ambiguity. The appeal to a 'blind spot' necessitating both rigorous self-examination and a 'third party', on the model of psychoanalysis, does not finally quite confront the problem, the horror (for a society seeking order and propriety) of the inherent ambiguity of meaning.

David G. Brooks offers a useful alternative image for the situation in his discussion of the important aspect of desire, both in the analysis of 'the neglected question of the reader's desire and ability to perceive ambiguity' (2) and in the drive towards disambiguation:

Hypothetically, this point where the text allows us no alternatives - where no further ambiguity seems to exist, where no choice of meaning seems apparent - is a point of 'truth,' a point of 'clarity.' But we can never be sure of this. We should all the time be prepared to find that what I have called the brick wall, when and if at last we reach it, may be in ourselves, and that the 'truth' is in this sense something we do not so much attain at last, as if it were a destination, an object, as it is a point of exhaustion of energy or imagination, something we can accept only provisionally, as a limit the nature of which is not itself ultimately knowable. (Brooks 2-3) 
Brooks argues that a certain will to perceive is necessary for ambiguity to become apparent, and that texts can thus appear unambiguous if that will is lacking. Furthermore, the ideal of complete disambiguation (what I am suggesting we should term the much looked-for, but un-named Unambiguity) is, in Brooks's account, a matter of running out of steam, or hitting a wall. Though apparently less interested in the politics of interpretation than Vaugeois, his metaphor of the wall is preferable in that it suggests negation, an inevitable exhaustion of options in one's own mind, rather than the image of the blind-spot, which suggests that simply shifting one's position will open up new perspectives, or that if we could only circumvent or transcend the limits imposed by our unavoidable situatedness, the goal of Unambiguity would be attainable.

Thus, Brooks suggests usefully that Unambiguity is not 'there' in the text, or for that matter in the realms of possibility, but is an effect of the interpreter's limitations, the end of his or her will to carry on seeking out multiple meanings and uncertainties. The only problem with this is that it can suggest that ambiguity exists entirely in the reader's willingness to find it, so that a text might correctly be found to be completely unambiguous, should its reader not be in the mood for ambiguity that day. That said, Brooks does seem to attempt a more dialectical sense of the objective and subjective determinants of ambiguity in his subsequent discussion (3-4), a necessary further stage to his argument, as the troubling ambiguity of our self-constituting medium, language, refuses to go away, tugging at our coat sleeves even when we no longer have the will to pay it any attention.

All three literary-critical theorists quoted here - Rojtman, Vaugeois and Brooks - in offering apparently different solutions to the problem of ambiguity, put forward arguments similar in structure to the case Žižek is often taken to be making, in which the fragile, ambiguity-ridden façade of reality masks a simpler, but (in Žižek's version) unbearable, Real - a Void at the heart of being which it is impossible for linguistic, socialised, beings to contemplate. In literary criticism, as in philosophy, the rickety construct of reality hides a simpler, and bigger, truth, although the hidden truth which literary critics sense behind the tracery of literary language is a good deal more comforting for bourgeois society than the horrifying 'Thing' so often glimpsed in Žižek's writings. But what if Unambiguity is not the hidden truth of language, which might in some moment of redemption be revealed (and which is obscurely hinted at in everyday symptomatic slips and confusions) but merely an aspect of the contorted, unbearable chaos of language, one false path amongst a million? Rojtman's account, in fact, seems to acknowledge this undecidability when she indicates that, whilst the random phenomena of the temporal world might signify some divine essence, equally they might not only at the end of the world will we know the answer, for this particular belief system. If we take up this second possibility, the Unambiguous is the most uncertain, unknowable, state of language and thus the most open to interpretation.

Meanwhile, for Žižek it is vital to grasp that even this widespread understanding of the relation of reality to the Real is not correct. Whilst we might like think of reality as a comforting distortion of the Real (as "the standard "Lacanian" notion' would have it (Žižek xxvii), a 'grimace of the Real', which crumples it into an anamorphic form which is more bearable and usable, for Žižek a more faithful reading of Lacan would acknowledge that

we are compelled to invert the formula quoted above: the Real itself is nothing but a grimace of reality: something which is nothing but a distorted perspective on reality, something which only shines through such a distortion, since it is "in itself" completely without substance. ... The Real is the appearance as appearance; it not only appears within appearances, it is also nothing but its own appearance - it is simply a certain grimace of reality, a certain imperceptible, unfathomable, ultimately illusory feature that accounts for the absolute difference within identity. ... From a materialist standpoint, the Thing is a spectre which emerges in the interstices of reality, in so far as reality is never homogeneous/consistent, but always afflicted by the cut of self-doubling. (Žižek xxvii-xxviii)

So, the Real is a grimace of reality - nothing more than the comforting fantasy that something exists beyond the perceptible, which intrudes into our world in uncanny form, seeming to explain the unsettlingly inconsistent nature of that reality. The Real is a rationalisation of the ever-present 'cut of self-doubling', the ways in which language, as a structure of absences and differences, continually gets in the way of itself, preventing the unambiguous creation and transfer of meaning. By analogy, rather than conceiving Ambiguity as a 'grimace' of a deeper, more genuine Unambiguity, Unambiguity should be thought of as the grimace of Ambiguity - a convenient invention to fill the literary critic's Void of generalised indeterminacy.

Here, we can return to the problem that was troubling Eleanor Cook about the older notion of 'ambiguity' and the new-fangled 'indeterminacy'. Seeking to defend use of the older term, she quotes Marjorie Perloff's statement that

Derridean readings of specific texts ... have a way of obscuring those essential differences (as opposed to "differance") that must, after all, concern those of us who are still interested in the relationships of particular literary works to each other. (Perloff 18)

Derrida's arguments, of course, redefine many of the words here, including 'relationships', 'literary' and 'works', in a way which is difficult to ignore. Nevertheless, if considered in the light of the dialectic of Ambiguity and Unambiguity, choosing 'ambiguity' over the deconstructors' preferred term has much to recommend it. Whilst 'indeterminacy' better denotes the impossibility of containing the play of meaning (owing to the infinite and shifting field of differential contexts), 'ambiguity' speaks precisely of the play of limitations. Ambiguity and Unambiguity are caught up in a dialectical relation, each defining and negating the other. They register the dilemma of the linguistic subject, 
caught within the structures of language and the forms of history. These limitations may be fantasies, but they are fantasies by means of which we dramatise the struggles of everyday historical existence, and which make up the stuff of literature and art.

\section{5. 'The Malady of the Quotidian' and Diseased Social Reality}

The 'reality' of everyday life, language and literature, consists of fragmented language, meaning and identity. Žižek reinforces this point when he writes that 'Language, in its very notion, involves a minimal distance towards its literal meaning - not in the sense of some irreducible ambiguity or multiple dispersion of meanings, but in the more precise sense of "he said X, but what if he really meant the opposite" (Žižek xiii): language is always distanced from itself because it is always possible, in one way or another, to use it to mean the opposite of what it 'should' mean. Ambiguity is always with us, not as the exception, but as the rule. Attempts to rationalise this situation, to make it understandable and bearable too often end up by making this disorderly situation more agreeable to the possessors of power and wealth.

Wallace Stevens' ambiguous phrase, 'the malady of the quotidian', from 'The Man Whose Pharynx Was Bad', with which Eleanor Cook illustrates the poetic use of ambiguity in prepositions, especially 'of' (Cook 236), evokes this situation powerfully. Cook takes this phrase to mean that the quotidian is endured or experienced as a malady - that to live through everyday life is to be sickened by it. In her reading, two causes of this idea are possible: the sheer dullness of routine, and the internal disease belonging to the person who experiences the everyday like that:

The time of year has grown indifferent.

Mildew of summer and the deepening snow

Are both alike in the routine I know.

I am too dumbly in my being pent.

The wind attendant on the solstices

Blows on the shutters of the metropoles,

Stirring no poet in his sleep, and tolls

The grand ideas of the villages.

The malady of the quotidian. ...

Perhaps, if winter once could penetrate

Through all its purples to the final slate,

Persisting bleakly in an icy haze,

One might in turn become less diffident,

Out of such mildew plucking neater mould

And spouting new orations of the cold.

One might. One might. But time will not relent.

However, just as one plausible meaning of 'mildew of summer' is the decay of summer, 'the malady of the quotidian' can refer to the disease of the everyday, the sickness which infects the texture of ordinary life, the relations within a community or social order, the quality of the social reality which people live out from day to day. In this interpretation, it is the quotidian itself - the ordinary relations of social life - which is ill. This sense of alienation is figured through the ambiguity of the season: the decay of the summer's richness and the deepening winter snows are poised in a way which provokes the speaker's ennui: 'both are alike in the routine I know'. Disgust at his enervating routine grows together with the disappointing lack of definition in the season, which fails to inspire the speaker with the poetic feelings traditionally associated with any of the seasons. Of course, it is not inevitable that the everyday should be boring, stressful or exploitative; it is just that for so many people in the era of capitalism, it is. Read in this way, the poem implies another, healthy, quotidian which may once have existed, and a renewed quotidian which might become possible in a transformed world. It acknowledges the political in its depiction of a desolate scene: social reality itself is sick and longs to be cured.

Despite this glimmer of hope, the conclusion of the poem seems pessimistic, though still ambiguous. Earlier, following the break at 'The malady of the quotidian. ...', there begins, with 'Perhaps', a middle phase which sounds considerably brighter than the downbeat opening. Unexpectedly, though, this insight into possibility does not imagine a renewed summer, or the conventional hopefulness of spring, but rather a winter which is more truly itself than the present uncertain season:

\section{Perhaps, if winter once could penetrate \\ Through all its purples to the final slate, \\ Persisting bleakly in an icy haze, \\ One might in turn become less diffident}

The speaker's diffidence could be cast aside if winter itself could achieve what another of Stevens's poems, 'The Snow Man', calls 'a mind of winter', or rather if it can 'penetrate' to some ultimate truth, 'the final slate' - bedrock, or that 'slate' on which some final account is kept. Bleak persistence is more authentic than the equivocal garments of the other seasons and their muddy intermingling around the solstices. The man whose pharynx was bad, if indeed he is the speaker, expresses a desire for Unambiguity - a realm beyond the sickly weather, beyond the coverings (mildewed vegetation, dustings or drifts of snow) which obscure the real nature of things. This is a quotidian existence in which meanings and intentions, both cosmic and interpersonal, are distressingly blurred.

The poem is, ultimately, however, sceptical about the prospect of such an Unambiguous epiphany becoming actual. It speaks through ambiguity of the relation between ambiguity and Unambiguity, and the sheer difficulty of resolving this dilemma. If winter could 'penetrate ... to the final slate',

One might in turn become less diffident,

Out of such mildew plucking neater mould

And spouting new orations of the cold.

One might. One might. But time will not relent. 
If things were clear again, if we were able to see through the 'icy haze' to the real, unambiguous, nature of things, a new, confident, eloquence - 'orations of the cold' - could be born from 'a new mould'. Here, mould, close kin to 'mildew', one might think, but also meaning perhaps soil or ground, is credited with neatness or lack of ambiguity; it can be both the fertile bed of new ideas, or the hollow form which gives definite shape to a molten mass. The resulting 'orations' are perhaps 'of' (issuing from) the cold itself, or perhaps 'of' (about) the cold understood as the realm of Unambiguity. 'Time', however, 'will not relent'. The unambiguity 'one might' be able to contemplate will never become available as there will always be that temporal lag, that deferral of meaning, that blurring of seasons, which keeps us trapped eternally in the ambiguous realm of the quotidian. Thus unfortunately, but in a way which allows us to understand the catastrophe, the poem, in its gloom, desires unmediated access to Unambiguity, and thus dooms itself to fail. It is tempting to conclude, therefore, that to embrace the ambiguity of social life, its striation with difference, would be to critique the ideological fiction of wise passiveness.

\section{Preparing to Exit: Saying Nothing to Nobody}

The words from To the Lighthouse which I took as my epigraph (describing Lily Briscoe's thoughts as she longs to rouse Mr Carmichael from his slumber), echo Žižek's description of this state in which 'language is "not all", because its limit is inscribed into it in the guise of ruptures in which the process of the enunciation intervenes in the enunciated.' (Žižek xiii) Lily is painfully aware that the situation of any utterance changes its meaning, that this inner 'tear' is always present.

Wanting to say 'everything', she finds that 'one could say nothing to nobody', which, although it sounds as if it might mean, 'one couldn't say anything to anybody', is in fact a much more interesting, and ambiguous, claim: 1) that nothing is all one can say, because language equally prevents one from saying both any 'one thing' and 'everything', 2) that it must be said to nobody, because no person, no socially functioning linguistic subject, would know what to do with 'nothing'. (It might be thought that she means 'nothing is something that one would not dare say to anybody', but equally it can mean the opposite: that 'nobody' is precisely the person to whom one can say this 'nothing'.) Thus, what might be taken as a moment at which Lily reaches an impasse and falls into despair, might rather be read as a moment of revelation. We might replace Eleanor Cook's Everyman-figure of the 'stranger', disconcerted by the ideologically-loaded 'reputation' of the glamorous Ambiguity, with this excellent 'nobody', a figure of the other with whom we can converse in the language of nothing. Nobody, with whom we can say 'nothing' (in other words, those unreliable, broken, communications which are all that is allowed by language), should perhaps become the protagonist of literary studies, a potential person who is, like us, forever in the unfinished, political, process of becoming. We might imagine, at least in a world of emancipated social relations, the ambiguous 'nothing' of our language, whether 'ordinary' or 'literary', as the language of that emancipation: a discourse in which the slipperiness of words need not spell the downfall of our neighbours, nor our own self-undoing.

If criticism cannot free itself from its double standard over ambiguity, though, it will always be marked by a tacit, ineffectual and politically regressive moralism. If it can reconcile itself to the incomplete project of reality without, consciously or unconsciously, basing its claims upon an unseen and idealised Unambiguity, it might stand a chance of contributing to that new world. Proper critique of the ideological role played by ambiguity in critical writing will help critics to deepen our experience and understanding, and, above all, to sharpen our awareness that the world needs to be altered. The economic and political forces which deprive life of its subtlety, its variety and its transformative power for so many are the enemies of poetry in its broadest and most meaningful sense.

\section{Notes}

1. See Cook, pp. 231-2; also 233 and f.n. 7; also Gerald Graff, 'Determinacy and Indeterminacy' in Critical Terms for Literary Study, eds. Frank Lentricchia and Thomas McLaughlin, Second Edition, Chicago: University of Chicago Press, 1995, pp. 163-76.

2. Cf. Jacques Derrida, 'Signature Event Context'. Glyph, vol I. Baltimore: Johns Hopkins University Press, 1977, pp. $172-97$.

\section{REFERENCES}

[1] Bishop, Elizabeth. 'Chemin de Fer', in Poems. London: Chatto, 2011, p. 10.

[2] Brooks, David G. 'Ambiguity, the Literary, and Close Reading'. CLCWeb: Comparative Literature and Culture, 12.4 (2010): http://docs.lib.purdue.edu/clcweb/vol12/iss4/9 Thematic Issue: Ambiguity in Culture and Literature. Eds. Paolo Bartoloni and Anthony Stephens (pages numbered 1-8).

[3] Cook, Eleanor. 'Ambiguity and the Poets', Connotations, 18, 1-3 (2008/2009), 230-45.

[4] Derrida, Jacques. 'Signature Event Context'. Glyph, vol. I. Baltimore: Johns Hopkins University Press, 1977, pp. 172-97.

[5] Empson, William. Seven Types of Ambiguity. Third Edition. London: Chatto, 1953.

[6] Gallagher, Tess. 'Instructions to the Double', in 20th Century Women's Poetry, ed. Fleur Adcock. London: Faber, 1987, pp. 277-8.

[7] Graff, Gerald. 'Determinacy and Indeterminacy' in Critical 
Terms for Literary Study, eds. Frank Lentricchia and Thomas McLaughlin. Second Edition. Chicago: University of Chicago Press, 1995, pp. 163-76.

[8] Leech, Geoffrey N. A Linguistic Guide to English Poetry. London: Longman, 1969.

[9] Nowottny, Winifred. The Language Poets Use. London: Athlone, 1962.

[10] Perloff, Marjorie. The Poetics of Indeterminacy: Rimbaud to Cage. Evanston: Northwestern University Press, 1999.

[11] Rojtman, Betty. 'Towards a Hermeneutics of Ambiguity: The Book of Esther and the Silence of Signs', trans. Jonathan Stavsky. Partial Answers: Journal of Literature and the History of Ideas, 10: 1, 2012, 1-10.
[12] Su, Soon Peng. Lexical Ambiguity in Poetry. London; Longman, 1994.

[13] Stevens, Wallace. 'The Man Whose Pharynx Was Bad', in The Collected Poems of Wallace Stevens. London: Faber, 1955 , p. 96.

[14] Stevens, Wallace. 'The Snow Man', in The Collected Poems of Wallace Stevens. London: Faber, 1955, pp. 9-10.

[15] Vaugeois, Dominique. 'Could you be more specific, please?' Neohelicon, 37, 2010: 441-48.

[16] Woolf, Virginia. To the Lighthouse. Harmondsworth: Penguin, 1964.

[17] Žižek, Slavoj. For They Know Not What They Do: Enjoyment as a Political Factor. Second Edition. London: Verso, 2002 